${ }^{1}$ School of Dentistry, Community University of Chapecó Region (Unochapecó), Chapecó, SC, Brazil.

${ }^{2}$ Private practice, Chapecó, SC, Brazil.

${ }^{3}$ Health Sciences Post-Graduate Program, Community University of Chapecó Region (Unochapecó), Chapecó, SC, Brazil.
Corresponding author: Prof. Dr. Sinval Adalberto Rodrigues-Junior,

Community University of Chapecó Region - Unochapecó, Área de Ciências da Saúde - Caixa postal 1141, Servidão Anjo da Guarda 295-D - Efapi, CEP 89809-000 - Chapecó - SC - Brazil; Phone number: +55 (49) 3321-8069; e-mail: rodriguesjunior.sa@ unochapeco.edu.br

Received: April 28, 2020

Accepted: December 9, 2020

\section{Effect of whitening mouth rinses on the chemical and physical properties of a nanofilled composite}

\author{
Laura Carolina Kepler ${ }^{1}$ iD, Ana Paula Morona \\ Rodrigues $^{2}$ (iD), Mauro Antonio Dall Agnol ${ }^{1}$ (iD, \\ Sinval Adalberto Rodrigues-Junior $3,^{*}$ (iD)
}

Aim: This study analyzed the effect of whitening mouth rinses on water sorption (WS), solubility (SL), color change, and surface roughness of a nanofilled composite. Whitening perceptibility and acceptability $\left(\mathrm{WI}_{\mathrm{D}}\right)$ were also studied. Methods: Forty specimens of Filtek Z350XT, shade EA2 were produced and randomly distributed $(n=8)$ to AS - artificial saliva (control); LWE - Listerine Whitening Extreme; CLW - Colgate Luminous White; LCM - Listerine Cool Mint; and CP - Colgate Plax. They were immersed in the mouth rinses $2 x /$ day, for one minute, during 28 days. The color was assessed using an Easyshade spectrophotometer (CIE-L*a*b* system). Surface roughness (Ra- $\mu \mathrm{m})$ was measured with three parallel measures, using an RP-200 roughness meter. The WS and SL $\left(\mu \mathrm{g} / \mathrm{mm}^{-3}\right)$ were analyzed based on the ISO 4049 recommendations. The data were analyzed using one- and two-way ANOVA/Tukey tests $(a=0.05)$. Results: Surface roughness significantly increased after immersion in AS and LCM, with no significant differences between the groups either before or after immersion. The $\Delta E^{\star}$ was not significantly different betweenthegroups. All substances produced a $\Delta W I_{D}$ higher than the $50 \%: 50 \%$ perceptibility and acceptability thresholds. The WS and SL were not significantly affected by the mouth rinses. Conclusion: Whitening mouth rinses did not affect WS, SL, surface roughness, and color stability of a nanofilled composite, regardless of the presence of ethanol in the composition.

Keywords: Tooth bleaching agents. Nonprescription drugs. Mouthwashes. Color. Composite resins. 


\section{Introduction}

Mouth rinse solutions are adjunct products for oral self-care. As such, most mouth rinses have an anti-microbial effect ${ }^{1}$ or a fluoride-releasing effect accounting for the control of the demineralization-remineralization process ${ }^{2}$. Mouth rinses also have become, since the 2000s, a means of attending to the growing cosmetic demand for tooth whitening. These over-the-counter products are acquired and administered by the patient, not requiring professional prescription and supervision during application ${ }^{3}$.

Whitening mouth rinses may present up to $2 \%$ of hydrogen peroxide ${ }^{4}$. Other substances, such as sodium hexametaphosphate, may help to prevent tooth surface staining ${ }^{5}$. Whitening mouth rinses also share similar substances with conventional mouth rinses, such as detergents, dyes, organic acids, emulsifiers, and alcohol ${ }^{6}$. Alcohol is not present in every mouth rinse but those containing it present antiseptic and preserving functions, besides dissolving active ingredients ${ }^{7}$.

Additionally, alcohol softens dimethacrylate-based resin composites, accelerating their degradation ${ }^{8}$. Anterior composite restorations have failed mostly due to esthetic reasons such as color change and surface staining ${ }^{9}$, and the esthetic appearance of dental restorations and its decrease are related to the hydrolytic degradation of the material ${ }^{10}$. The effect of an alcohol-containing mouth rinse on the solubility of a dimethacrylate-based composite has been shown but in conditions that do not emulate the clinical use of the mouth rinse ${ }^{11}$. Therefore, the extent of degradation triggered by the alcohol present in mouth rinses in daily mouthwashes of one to two minutes remains unclear.

The hydrogen peroxide present in some whitening mouth rinses has produced a whitening effect on previously stained composites ${ }^{12}$. This occurs when the whitener breaks dark complex molecules of pigment into simpler structures with lighter optical properties ${ }^{12}$. It is noteworthy that a significant whitening effect only occurs in the presence of acquired extrinsic stains and it is not an issue when the composite is not extrinsically pigmented ${ }^{12,13}$ According to Goldberg et al. ${ }^{14}$ (2010), hydrogen peroxide increases the leaching of components from amalgam and fluoride-containing restorative materials, affecting the bond interface between composite and bleached dentin. Nevertheless, the effect of hydrogen peroxide on composite degradation is not fully established, requiring further research. Additionally, the level of perceptibility and acceptability of the composite color change from the contact with mouth rinses, from a viewer standpoint, must be explained ${ }^{13}$.

Considering the likelihood of substances contained in whitening mouth rinses to potentially help the degradation of composites, expectations are that surface and bulk properties such as color change and surface roughness are affected by contact with these oral hygiene products. Therefore, this study aimed to test the hypothesis that whitening mouth rinses affect the chemical and physical properties of a nanofilled universal composite resin.

\section{Materials and Methods}

Forty disc-shaped specimens with $10 \mathrm{~mm}$ of diameter (D) and $2 \mathrm{~mm}$ of height (h) were produced with the Filtek Z350XT nanofilled composite (shade EA2, 3M/ESPE, St. Paul, MN, USA) using a circular stainless steel mold (Odeme, Luzerna, SC, Brazil). The specimens were light-cured with 20-second overlapped light exposures on the top and 
bottom surfaces, according to the ISO $4049^{15}$ recommendations. An LED light-curing unit (Ultraled, Dabi Atlante, Ribeirão Preto, SP, Brazil) was used and had its light irradiance monitored the beginning and end of each specimen build-up session using an LED radiometer (ECEL, Ribeirão Preto, SP, Brazil) - mean irradiance of $1193 \mathrm{~mW} / \mathrm{cm}^{2}$.

The specimens were finished with a \#400 sandpaper and had their dimensions measured with a digital caliper (Mitutoyo Corporation, Kanagawa, Japan) and averaged based on the ISO 4049 recommendations ${ }^{15}$. The diameter was cross-measured and averaged from the two measures, while the height was measured in five points (four extremities and one in the center). These measures were used to calculate the volume of each specimen: $V=\pi \cdot R^{2}$. h, where $\mathrm{R}$ is the specimen radius $(\mathrm{D} / 2)$.

\section{Intervention protocol (mouth rinses)}

The specimens were randomly allocated into five groups $(n=8)^{16}$ using an online random number generator (www.random.org). Grouping involved two whitening mouth rinses and two conventional (non-whitening) mouth rinses, along with a negative control group: AS- artificial saliva (control); LWE- Listerine Whitening Extreme; CLW- Colgate Luminous White; LCM- Listerine Cool Mint; and CP- Colgate Plax. The artificial saliva was prepared in the institutional Pharmacology Laboratory, by a pharmacology technician, based on the formulation developed by the School of Pharmaceutical Sciences of the São Paulo State University (Table 1). The pH of the substances was measured in the same laboratory, in duplicate, using a pH meter (Q-400A, Quimis Aparelhos Científicos Ltda., Diadema, SP, Brazil) previously calibrated with standard solutions. Table 1 presents the compositions of the substances used in the study. The specimens were immersed daily, twice a day, for one minute in the solutions, for 28 days. During the treatment, the specimens were stored in artificial saliva at $37^{\circ} \mathrm{C}$, which was changed once a day.

Table 1. Materials used in the study

\begin{tabular}{|c|c|c|c|}
\hline Product & Manufacturer & Components & $\mathrm{pH}$ \\
\hline Filtek Z350XT & $\begin{array}{c}\text { 3M/ESPE, St. Paul, MN, } \\
\text { USA }\end{array}$ & $\begin{array}{c}\text { Bis-GMA*, Bis-EMA }(6)^{\star}, \text { UDMA }^{*}, \text { TEGDMA* } 78.5 \% \text { of filler } \\
\text { particles in weight (clusters of } 0.6-1.4 \mu \mathrm{m} \text { - individual } \\
\text { particle size of } 5-20 \mathrm{~nm} \text { ) - silica and zirconia }\end{array}$ & - \\
\hline $\begin{array}{l}\text { Artificial saliva } \\
\left.\text { (Santos }^{17} 2008\right)\end{array}$ & $\begin{array}{l}\text { Institutional } \\
\text { Pharmacology } \\
\text { Laboratory }\end{array}$ & $\begin{array}{c}\text { Potassium chloride, sodium chloride, magnesium chloride, } \\
\text { potassium phosphate, calcium chloride, nipagin, nipasol, } \\
\text { carboxymethylcellulose, sorbitol, distilled water }\end{array}$ & 5.3 \\
\hline Colgate Plax & $\begin{array}{l}\text { Colgate-Palmolive, São } \\
\text { Bernardo do Campo, } \\
\text { SP, Brazil }\end{array}$ & $\begin{array}{l}\text { Water, glycerin, propylene glycol, sorbitol, poloxamer } 338 \text {, } \\
\text { poloxamer } 407 \text {, aroma, PEG-40 hydrogenated castor oil, } \\
\text { cetylpyridinium chloride, potassium sorbate, sodium fluoride, } \\
\text { sodium saccharin, citric acid, sucralose, Cl } 42053\end{array}$ & 4.8 \\
\hline $\begin{array}{l}\text { Listerine Cool } \\
\text { Mint }\end{array}$ & $\begin{array}{l}\text { Johnson \& Johnson } \\
\text { Industrial Ltda., Yumbo, } \\
\text { Valle, Colombia }\end{array}$ & $\begin{array}{l}\text { Water, sorbitol, alcohol, poloxamer 407, benzoic acid, sodium } \\
\text { saccharin, eucalyptol, aroma (d-limonene), thymol, methyl } \\
\text { salicylate, sodium benzoate, menthol, } \mathrm{Cl} 42053\end{array}$ & 4.2 \\
\hline $\begin{array}{l}\text { Colgate } \\
\text { Luminous } \\
\text { White }\end{array}$ & $\begin{array}{l}\text { Colgate-Palmolive, São } \\
\text { Bernardo do Campo, } \\
\text { SP, Brazil }\end{array}$ & $\begin{array}{c}\text { Water, glycerin, propylene glycol, sorbitol, tetrapotassium } \\
\text { pyrophosphate, polysorbate } 20 \text {, tetrasodium pyrophosphate, } \\
\text { zinc citrate, PVM/MA copolymer, aroma, benzyl alcohol, } \\
\text { sodium fluoride, sodium saccharin, Cl } 42051\end{array}$ & 7.2 \\
\hline $\begin{array}{l}\text { Listerine } \\
\text { Whitening } \\
\text { Extreme }\end{array}$ & $\begin{array}{l}\text { Johnson \& Johnson } \\
\text { Industrial Ltda., Yumbo, } \\
\text { Valle, Colombia }\end{array}$ & $\begin{array}{l}\text { Water, alcohol, } 2.5 \% \text { hydrogen peroxide, aroma, poloxamer } \\
407 \text {, sodium saccharin, menthol, phosphoric acid, disodium } \\
\text { phosphate, sodium fluoride, sucralose }\end{array}$ & 3.5 \\
\hline
\end{tabular}

* Bis-GMA=bisphenol A-glycidyl methacrylate, Bis-EMA=bisphenol A diglycidyl methacrylate ethoxylated,

TEGDMA=triethylene glycol dimethacrylate, UDMA=urethane dimethacrylate 


\section{Water sorption and solubility test}

To determine water sorption and the solubility of the composite after the mouth rinse protocol, the specimens were first dried, stored in a desiccator containing silica gel at $37^{\circ} \mathrm{C}$, and weighted daily to check for mass stabilization (dry mass, $\mathrm{m}_{1}$ ). Then, the specimens were submitted to the mouth rinse application protocols and stored in artificial saliva. At the end of the 28-day application period, the specimens were reweighted to obtain the wet mass $\left(m_{2}\right)$. Finally, the specimens were stored in the desiccator at $37^{\circ} \mathrm{C}$ again and weighted until they reached a new stable dry mass $\left(\mathrm{m}_{3}\right)$. An analytical balance with 0.1-mg accuracy (AUW220D; Shimadzu Corporation, Kyoto, Japan) was used to weigh the specimens. Water sorption (WS) and solubility (SL) were expressed as $\mu \mathrm{g} / \mathrm{mm}^{-3}$ and calculated as follows: $W S=m_{2}-m_{3} / V$ and $S L=m_{1}-m_{3} / V^{15}$.

\section{Surface roughness test}

The mean surface roughness $(\mathrm{Ra})$ was measured by three parallel surface readings along a 4-mm length (cut-off $=0.8 \mathrm{~mm}$ ) in the top surface of the specimen. A roughness meter RP200 (Instrutherm, São Paulo, SP, Brazil) was used to read the surface roughness before and after the mouth rinse application protocol ${ }^{18}$.

\section{Color change analysis}

The color was read before and after the 28-day application protocol, using an Easyshade portable digital spectrophotometer (Vita Zahnfabrik, Bad Säckingen, Germany). The specimens were positioned over a white background under the same lighting conditions, and the color was read by positioning the spectrophotometer probe perpendicular to the specimen's surface. The color results were expressed based on the three-dimensional CIEL*a*b* system. This system considers three color parameters, represented by three axes. The $L^{*}$ axis represents luminosity and varies from 0 (black) to 100 (white), the $a^{*}$ axis represents the color variation between red (a* positive) and green ( $a^{\star}$ negative), and the $b^{\star}$ axis varies between yellow ( $b^{\star}$ positive) and blue ( $b^{*}$ negative). Color change in these axes is represented by $\Delta \mathrm{L}^{*}, \Delta \mathrm{a}^{*}$, and $\Delta \mathrm{b}^{*}$, which are used to calculate the ultimate general color change $\left(\Delta E^{\star}\right)$ through the equation:

$$
\Delta E_{a b}^{\star}=\sqrt{\left(L_{2}^{*}-L_{1}^{*}\right)^{2}+\left(a_{2}^{*}-a_{1}^{*}\right)^{2}+\left(b_{2}^{*}-b_{1}^{*}\right)^{2}}
$$

The 50\%:50\% perceptibility and acceptability thresholds for color change of 1.2 and 2.7 were used, respectively ${ }^{19}$.

Also based on the CIEL*a*b* three-dimensional color space, the Whitening Index for Dentistry $\left(\mathrm{WI}_{\mathrm{D}}\right)^{20}$ was calculated to generate the $\Delta \mathrm{WI} \mathrm{I}_{\mathrm{D}}$, which represents the difference of whiteness before and after treatment with the mouth rinses.

$$
W I_{D}=0.511 L^{*}-2.324 a^{*}-1.100 b^{*}
$$

For the $\Delta \mathrm{WI}_{D^{\prime}} 50 \%: 50 \%$ perceptibility and acceptability thresholds of 0.61 and 2.90 were used, respectively ${ }^{19}$.

\section{Statistical analysis}

First, the data were verified for normal distribution and equal variances. Outliers were recognized using Grubb's test and removed from the dataset. The data of surface 
roughness, water sorption, solubility, $\Delta \mathrm{a}^{*}, \Delta \mathrm{b}^{*}, \Delta \mathrm{L}^{*}, \Delta \mathrm{E}^{*}$, and $\Delta \mathrm{WI} \mathrm{D}_{\mathrm{D}}$ were analyzed with one-way analysis of variance (ANOVA). The data of $a^{*}, b^{*}, L^{*}$, and $W I_{D}$ were analyzed with two-way ANOVA, considering the immersion substances and time as factors. For these analyses, Tukey's complementary test was applied and the level of significance of all analyses was $a=0.05$.

\section{Results}

The mouth rinse application protocol did not show a significant effect either for composite water sorption $(p=0.656)$ or solubility $(p=0.207)$ (Figure 1$)$. Surface roughness significantly increased after immersion in saliva $(p=0.023)$ and Listerine Cool Mint $(p=0.011)$ (Figure 2).

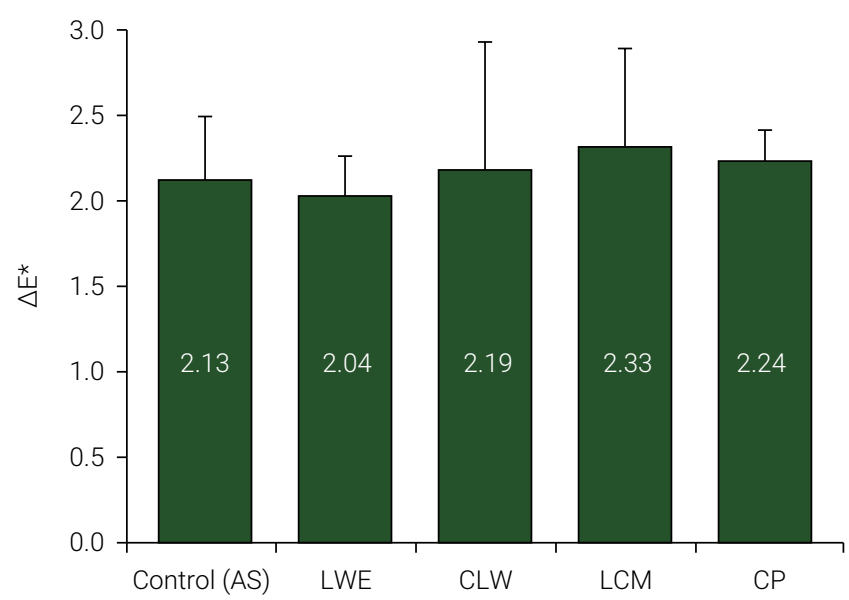

Figure 1. Water sorption and solubility of the nanocomposite Filtek Z350 after application protocol in whitening and conventional mouth rinses

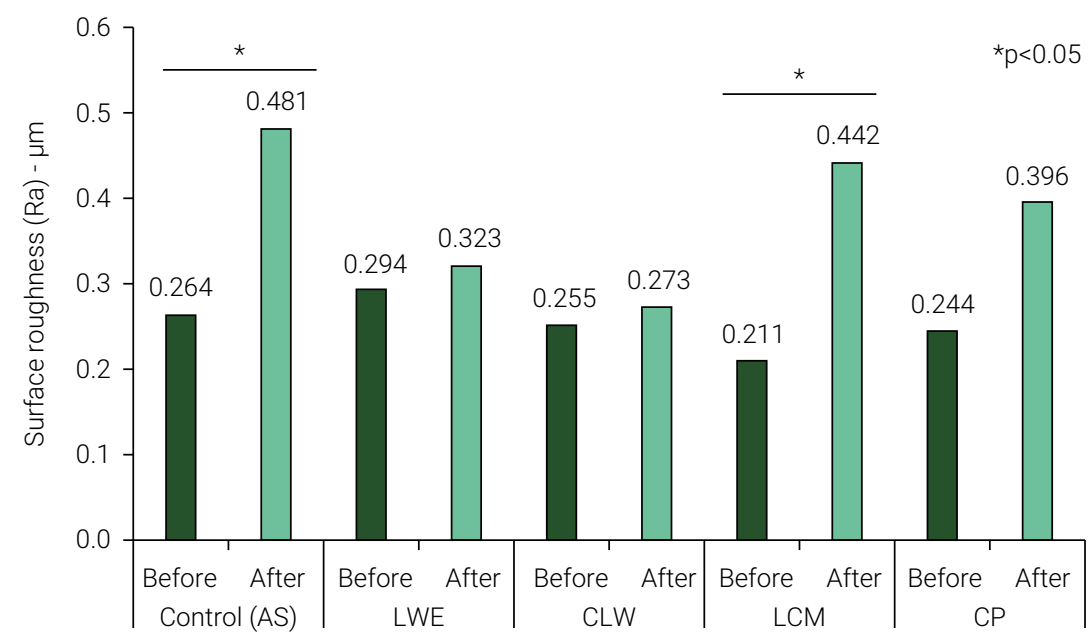

Figure 3. Color change $\left(\Delta \mathrm{E}^{\star}\right)$ of the nanocomposite Filtek Z350 after application protocol in whitening and conventional mouth rinses 
Table 2 presents the color results considering the $L^{*}, a^{*}$, and $b^{*}$ parameters, and color change was expressed as $\Delta L^{*}, \Delta a^{*}$, and $\Delta b^{*}$. Luminosity $\left(L^{*}\right)$ was significantly affected by the immersion substances $(p=0.018)$ but not by time $(p=0.654)$ or the interaction between both $(p=0.915)$. The $\Delta L^{\star}$ was not significantly affected by the immersion substances $(p=0.667)$. The $a^{\star}$ was significantly affected by the immersion substances $(p<0.001)$, time $(p<0.001)$, and the interaction between both $(p=0.009)$. The a* reduced after the 28 -day immersion period and $\Delta a^{*}$ was significantly affected by the immersion substances $(p=0.004)$, with Colgate Plax producing the highest $\triangle a^{*}$. As for $b^{\star}$, it was significantly affected by the immersion substances $(p=0.024)$ and time $(p<0.001)$ but not the interaction between both $(p=0.692)$. Immersion time reduced $b *$ and artificial saliva produced the lowest $b *$. No significant difference was observed in $\triangle b^{\star}$ between the groups $(p=0.945)$. Overall color change $\left(\Delta E^{\star}\right)$ was not significantly different between the groups $(p=0.805)$ (Figure 3$)$. The color change results of all groups were higher than the perceptibility threshold but lower than the acceptability threshold.

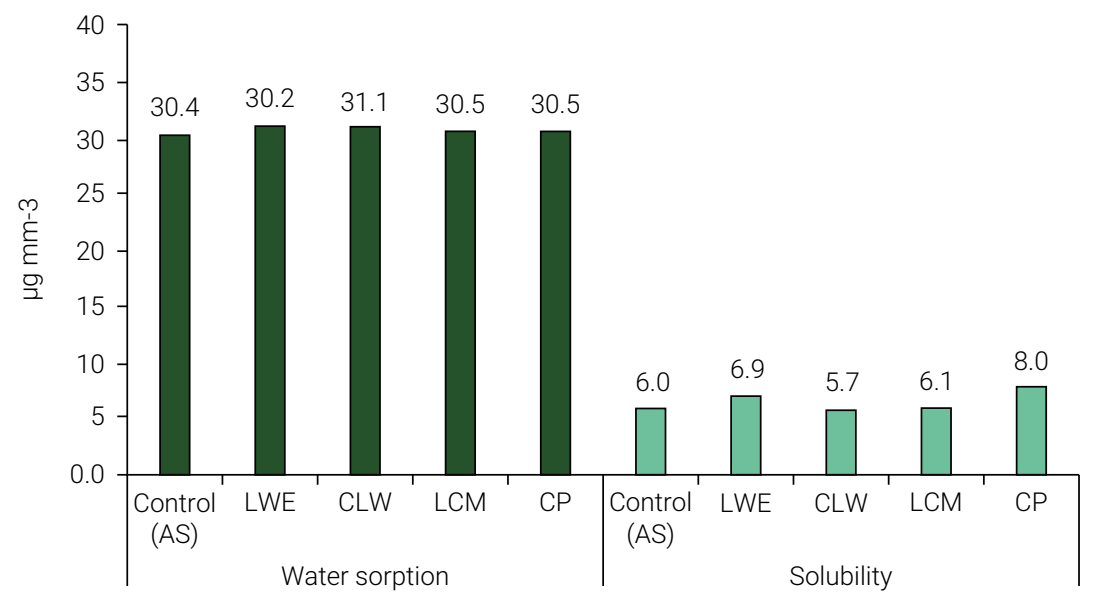

Figure 3. Color change $\left(\Delta \mathrm{E}^{\star}\right)$ of the nanocomposite Filtek Z350 after application protocol in whitening and conventional mouth rinses

Table 2. Color parameters $L^{*}, a^{*}$ and $b$ * of the nanofilled composite Filtek Z350XT before and after application protocol in whitening and conventional mouth rinses

\begin{tabular}{llll}
\hline Color parameter & $\begin{array}{c}\text { Baseline } \\
\text { Mean (SD) }\end{array}$ & $\begin{array}{c}\text { 28-day } \\
\text { Mean (SD) }\end{array}$ & $\begin{array}{c}\Delta \\
\text { Mean (SD) }\end{array}$ \\
\hline $\mathrm{L}^{*}$ & $81.2(0.8)_{\mathrm{a}, \mathrm{A}}$ & $81.1(0.7)_{\mathrm{a}, \mathrm{A}}$ & $-0.025(0.315)_{\mathrm{A}}$ \\
\hline $\mathrm{AS}$ & $81.7(1.0)_{\mathrm{a}, \mathrm{AB}}$ & $81.6(0.7)_{\mathrm{a}, \mathrm{AB}}$ & $-0.050(1.016)_{\mathrm{A}}$ \\
\hline $\mathrm{LWE}$ & $81.7(0.7)_{\mathrm{a}, \mathrm{AB}}$ & $81.8(0.6)_{\mathrm{a}, \mathrm{AB}}$ & $0.100(0.674)_{\mathrm{A}}$ \\
\hline $\mathrm{CLW}$ & $81.9(0.4)_{\mathrm{a}, \mathrm{B}}$ & $81.9(0.5)_{\mathrm{a}, \mathrm{B}}$ & $-0.037(0.498)_{\mathrm{A}}$ \\
\hline $\mathrm{LCM}$ & $81.1(0.8)_{\mathrm{a}, \mathrm{AB}}$ & $81.5(0.8)_{\mathrm{a}, \mathrm{AB}}$ & $0.386(0.445)_{\mathrm{A}}$ \\
\hline $\mathrm{CP}$ & &
\end{tabular}


Continuation

\begin{tabular}{llll}
\hline $\mathrm{a}^{*}$ & & & \\
\hline $\mathrm{AS}$ & $1.2(0.1)_{\mathrm{a}, \mathrm{A}}$ & $0.8(0.1)_{\mathrm{b}, \mathrm{A}}$ & $-0.438(0.092)_{\mathrm{A}}$ \\
\hline LWE & $1.2(0.3)_{\mathrm{a}, \mathrm{A}}$ & $0.8(0.1)_{\mathrm{b}, \mathrm{A}}$ & $-0.314(0.146)_{\mathrm{A}}$ \\
\hline $\mathrm{CLW}$ & $1.2(0.3)_{\mathrm{a}, \mathrm{A}}$ & $0.7(0.1)_{\mathrm{b}, \mathrm{A}}$ & $-0.500(0.330)_{\mathrm{AB}}$ \\
\hline LCM & $1.3(0.3)_{\mathrm{a}, \mathrm{A}}$ & $0.7(0.1)_{\mathrm{b}, \mathrm{A}}$ & $-0.587(0.394)_{\mathrm{AB}}$ \\
\hline $\mathrm{CP}$ & $0.9(0.1)_{\mathrm{a}, \mathrm{B}}$ & $-0.01(0.1)_{\mathrm{b}, \mathrm{B}}$ & $-0.871(0.160)_{\mathrm{B}}$ \\
\hline $\mathrm{b}^{*}$ & & & \\
\hline AS & $20.9(0.2)_{\mathrm{a}, \mathrm{A}}$ & $-2.062(0.374)_{\mathrm{A}}$ \\
\hline LWE & $21.2(0.3)_{\mathrm{a}, \mathrm{B}}$ & $18.8(0.3)_{\mathrm{a}, \mathrm{A}}$ & $-1.829(0.150)_{\mathrm{A}}$ \\
\hline CLW & $19.5(0.3)_{\mathrm{a}, \mathrm{B}}$ & $-1.900(1.009)_{\mathrm{A}}$ \\
\hline LCM & $21.0(0.6)_{\mathrm{a}, \mathrm{AB}}$ & $19.1(0.5)_{\mathrm{a}, \mathrm{AB}}$ & $-2.063(0.918)_{\mathrm{A}}$ \\
\hline CP & $21.0(0.6)_{\mathrm{a}, \mathrm{AB}}$ & $18.9(0.5)_{\mathrm{a}, \mathrm{AB}}$ & $-1.986(0.146)_{\mathrm{A}}$ \\
\hline
\end{tabular}

Lower case letters represent the comparison of groups in lines; capital letters represent the comparison of groups in columns; different letters reveal statistically significant differences in comparisons

Table 3 presents the results of $\mathrm{WI}_{\mathrm{D}}$ and $\Delta \mathrm{WI}_{\mathrm{D}}$. The statistical analysis of the $\mathrm{WI}_{\mathrm{D}}$ data revealed that the immersion substance $(p<0.001)$, time $(p<0.001)$, and the interaction between both $(p=0.001)$ significantly affected $W I_{D}$. The $\mathrm{WI}_{\mathrm{D}}$ significantly increased in all groups after the 28-day immersion protocol. The highest $\Delta \mathrm{WI}$, was observed in the Colgate Plax conventional mouth rinse. All substances, including saliva, produced a $\triangle \mathrm{WI}$ Digher than the 50\%:50\% perceptibility and acceptability thresholds.

Table 3. $\mathrm{WI}_{\mathrm{D}}$ and $\Delta \mathrm{WI}_{\mathrm{D}}$ of the nanofilled composite Filtek Z350XT before and after application protocol in whitening and conventional mouth rinses

\begin{tabular}{lccc}
\hline Whiteness parameter & \multicolumn{2}{c}{ WI $_{\mathrm{D}}$} & \multicolumn{1}{c}{$\begin{array}{c}\Delta \mathrm{WI}_{\mathrm{D}} \\
\text { Mean (SD) }\end{array}$} \\
\cline { 2 - 5 } & $\begin{array}{c}\text { Baseline } \\
\text { Mean (SD) }\end{array}$ & $\begin{array}{c}\text { 28-day } \\
\text { Mean (SD) }\end{array}$ \\
\hline AS & $15.7(0.4)_{\mathrm{a}, \mathrm{AB}}$ & $19.0(0.6)_{\mathrm{b}, \mathrm{AB}}$ & $-3.3(0.6)_{\mathrm{A}}$ \\
\hline LWE & $15.6(0.6)_{\mathrm{a}, \mathrm{A}}$ & $18.5(0.5)_{\mathrm{b}, \mathrm{A}}$ & $-2.9(0.4)_{\mathrm{A}}$ \\
\hline CLW & $15.9(0.4)_{\mathrm{a}, \mathrm{AB}}$ & $19.2(0.5)_{\mathrm{b}, \mathrm{AB}}$ & $-3.3(0.9)_{\mathrm{A}}$ \\
\hline CP & $15.8(0.4)_{\mathrm{a}, \mathrm{B}}$ & $19.4(0.7)_{\mathrm{b}, \mathrm{B}}$ & $-3.6(0.6)_{\mathrm{AB}}$ \\
\hline
\end{tabular}

Lower case letters represent the comparison of groups in lines; capital letters represent the comparison of groups in columns; different letters reveal statistically significant differences in comparisons

\section{Discussion}

Mouth rinses are adjunct over-the-counter substances for mouth cleansing. Whitening mouth rinses supposedly present a tooth whitening effect, mainly produced by substances such as hydrogen peroxide ${ }^{5,21}$. Considering the acquisition of mouth rinses does not require a professional prescription, anybody can use them, including individuals with esthetic dental restorations. Therefore, understanding the effect of whitening mouth rinses in tooth-colored restorations is important to correctly advise 
those who have them about possible impacting adverse effects such as increased roughness or restoration color change. Our results revealed no significant effect of conventional and whitening mouth rinses on water sorption and solubility of the composite. Moreover, the greatest changes in surface roughness occurred in the control group and with one of the conventional mouth rinses, also revealing no significant effect of whitening mouth rinses on this property. Finally, the overall color change was not significantly affected by either mouth rinse. Therefore, the study hypothesis that whitening mouth rinses would affect the chemical and physical properties of a nanofilled composite resin was rejected.

No difference was observed in the water sorption and solubility of the composite resin in the different groups (Figure 1). Both are related to hydrolytic degradation, which mediates the deterioration of other properties of composite resins over time, affecting surface and bulk properties of the restoration ${ }^{10,22}$. Water uptake within the polymer chains through voids leads to the cleavage of links that form polymers, producing smaller-sized molecules such as oligomers and monomers, which may be leached to the environment ${ }^{18}$. Additionally, it causes a hygroscopic expansion of the material, ultimately resulting in the solubilization of other molecules such as fillers, catalysts, and unreacted monomers ${ }^{10}$. In this study, neither the presence of whiteners from some mouth rinses nor alcohol from others affected the extension of polymer degradation, as expressed by water sorption and solubility. The latter could have affected polymer chains differently, as it has been shown that aqueous solutions that associate water and ethanol potentiate polymer degradation due to the similarity of the solubility parameter with the polymer ${ }^{10}$. An ethanol-containing mouth rinse was previously identified for increasing the solubility of a dimethacrylate-based composite. However, these results were obtained with the authors storing the specimens for two days in contact with the mouth rinse ${ }^{11}$, while our study limited the contact with the mouth rinse to two minutes daily. Under these conditions, which simulate one month of mouth rinse application twice a day, water sorption results were considered acceptable for all groups, considering the parameters set by the ISO 4049. Regarding solubility, the conventional mouth rinse group was the only one to produce solubility results above those considered acceptable by the ISO 4049 standards $\left(7.5 \mu \mathrm{g} \mathrm{mm}^{-3}\right)^{15}$, suggesting a higher solubilizing effect on the composite resin.

Surface smoothness is an important aspect of esthetic dental restorations. It affects color by reflecting light differently and mechanically retaining surface stains ${ }^{6}$. Polishing with a \#400 sandpaper ensured a baseline surface roughness lower than $0.3 \mu \mathrm{m}$, which in turn increased to almost $0.5 \mu \mathrm{m}$ in the negative control group consisting of artificial saliva and one of the conventional mouth rinses containing alcohol (Figure 2). The presence of hydrogen peroxide or ethanol in the mouth rinses did not seem to have affected surface roughness results. Therefore, using whitening or alcohol-containing mouth rinses does not seem an issue for the surface roughness of dental restorations, considering the total daily application time of two minutes. Moreover, the presence of acidic substances such as phosphoric acid has been considered to affect the organic matrix of the composite ${ }^{23}$. Except for Colgate Luminous White, all other substances presented a low pH. Curiously, the substance with the lowest $\mathrm{pH}$ and the presence of phosphoric acid (Listerine Whitening Extreme) did not affect significantly 
the surface roughness of the composite studied. Munchow et al. ${ }^{24}$ (2014), testing the effect of substances with varying acidic potentials on the surface degradation of composite resins, observed that all the substances affected similarly the surface roughness of the composite. According to the authors, factors such as the solubility parameter of the solvent and material, the cross-linked nature of the resin matrix, and solvent uptake may explain better the surface deterioration of the composite resin. The last two factors were similar in this study, leaving the first factor to explain the differences found for surface roughness in some of the groups tested.

The results of this study revealed no significant overall color change in the nanofilled composite after mouth rinse immersions, including the whitening ones (Figure 3). The color of tooth-colored restorations is usually a concern after tooth whitening, requiring a restoration replacement after tooth whitening is finished ${ }^{13}$. Recent studies showed that perceptible color change $\left(\Delta \mathrm{E}^{\star}\right)$ might be induced by tooth whitening substances when extrinsically acquired stains are impregnated in the restoration ${ }^{12,25}$. However, lower thresholds were set recently for 50\%:50\% perceptibility and acceptability of color change. These thresholds aid dental patients and set values of 1.2 for perceptibility and 2.7 for acceptability based on the perception of a layperson ${ }^{19}$. In this recent scenario, even the color change results by Farinon et al. from water storage would be considered perceptible by a layperson standpoint, as well as our color change results after immersions in mouth rinses and artificial saliva. These values would also be considered acceptable taking the recent 50\%:50\% threshold for acceptability ${ }^{19}$, making it unlikely to require a restoration replacement after applying the mouth rinse twice a day for one month, regardless of the type of mouth rinse.

It is noteworthy that the presence of $2.5 \%$ hydrogen-peroxide in Listerine Whitening Extreme did not play a role in color change, producing the lowest nominal $\Delta \mathrm{E}^{\star}$ value of all groups. This lack of significant influence of a whitening substance in the mouth rinse may again be explained by the absence of extrinsic staining agents in the composite resin ${ }^{12,25}$, causing minimum color changes and unlikely presenting clinical significance ${ }^{25}$. The overall color change was mainly driven by the reduction in $a^{*}$ and $b^{\star}$ axes values, which leads to color changes towards green in the $a^{*}$ axis and towards blue in the $b^{\star}$ axis. Both sets of mouth rinses (Colgate and Listerine) present pigments with a blueish/greenish color that could have caused color changes in these axes, despite the low contact time with the composite ${ }^{23}$.

The $\mathrm{WI}_{\mathrm{D}}$ significantly increased after the 28-day immersion protocol in all groups (Table 3). According to Pérez et al. ${ }^{20}$ (2016), the $\mathrm{WI}_{\mathrm{D}}$ is the best approximation of the visual perception of whiteness based on a set of psychophysical experiments. It depends on the $L^{*}, a^{*}$, and $b^{*}$ coordinates of the three-dimensional color space. Expectations were that a reduced variation in $L^{*}$ would produce an insignificant perception of whiteness before and after the immersion protocol, as previously observed ${ }^{22}$. However, our results showed that variations of $a^{*}$ and $b^{*}$ produced $\Delta W I_{D}$ results varying from 2.9 to 4.4 towards a whiter material. Most importantly, the $\Delta W I_{D}$ results correspond to values higher than the 50\%:50\% perceptibility and acceptability thresholds for whiteness perception ${ }^{22}$, meaning that dental restorations may be perceived whiter after contacting the substances studied. 
We methodologically decided to include a control group constituted by artificial saliva to reveal possible changes in properties that could have been caused by common substances in conventional and whitening mouth rinses. We also attempted to simulate a relevant clinical regimen of mouth rinse application involving daily applications, twice a day, for one minute ${ }^{26}$. The methodological limitations involved the light-curing protocol, which followed the recommendations of the ISO 4049 and did not reflect the real light-curing conditions when a dental restoration is built-up. Müller et al. ${ }^{27}$ (2017) highlight the role of product standards in providing in vitro reproducible test designs to characterize materials. They also call attention to the limited evidence on the clinical performance of these materials, suggesting further clinical approaches to confirm the in vitro results obtained.

The results of this study suggest that whitening mouth rinses would interact with a composite resin similar to regular mouth rinses, not producing any additional deleterious effect on restorations. The study hypothesis was rejected because water sorption, solubility, surface roughness, and color of a densely polymerized nanofilled composite are not affected by a one-month mouth rinse application protocol with either whitening or conventional mouth rinses.

\section{Acknowledgements}

This study was funded by FAPESC, grant no. 06/2017.

\section{References}

1. DeVore LR. Antimicrobial mouthrinses: impact on dental hygiene. J Am Dent Assoc. 1994 Aug;125 Suppl 2:23S-28S. doi: 10.1016/s0002-8177(94)14004-5.

2. Marinho VCC, Chong LY, Worthington HV, Walsh T. Fluoride mouthrinses for preventing dental caries in children and adolescents. Cochrane Database Syst Rev. 2016 Jul 29;7(7):CD002284. doi: 10.1002/14651858.CD002284.pub2.

3. ADA Council on Scientific Affairs. Tooth whitening/bleaching: treatment considerations for dentists and their patients. Chicago: ADA; 2009 Sep. p.1-12.

4. Demarco FF, Meireles SS, Masotti AS. Over-the-counter whitening agents: Critical assessment of the OTC products for home-use bleaching. Braz Oral Res. 2009 Jun;23(Suppl 1):64-70. doi: 10.1590/S1806-83242009000500010.

5. Lima FG, Rotta TA, Penso S, Meireles SS, Demarco FF. In vitro evaluation of the whitening effect of mouth rinses containing hydrogen peroxide. Braz Oral Res. 2012 May-Jun;26(3):269-74. doi: 10.1590/s1806-83242012000300014.

6. Cengiz S, Yuzbasioglu E, Cengiz MI, Velioglu N, Sevimli G. Color stability and surface roughness of a laboratory-processed composite resin as a function of mouthrinse. J Esthet Dent. 2015;27(5):314-21. doi: $10.1111 /$ jerd. 12167 .

7. Lemos-Júnior CA, Villoria GEM. Reviewed evidence about the safety of the daily use of alcohol-based mouthrinses. Braz Oral Res. 2008;22 Suppl 1:24-31. doi: 10.1590/s1806-83242008000500005.

8. Schneider LFJ, Moraes RR, Cavalcante LM, Sinhoreti MAC, Correr-Sobrinho L, Consani S. Cross-link density evaluation through softening tests: effect of ethanol concentration. Dent Mater. 2008 Feb;24(2):199-203. doi: 10.1016/j.dental.2007.03.010. 
9. Demarco FF, Collares K, Coelho-de-Souza FH, Correa MB, Cenci MS, Moraes RR, et al. Anterior composite restorations: a systematic review on long-term survival and reasons for failure. Dent Mater. 2015 Oct;31(10):1214-24. doi: 10.1016/j.dental.2015.07.005.

10. Ferracane JL. Hygroscopic and hydrolytic effects in dental polymer networks. Dent Mater. 2006 Mar;22(3):211-22. doi: 10.1016/j.dental.2005.05.005.

11. Ozer S, Tunc ES, Tuloglu N, Bayrak S. Solubility of two resin composites in different mouthrinses. Biomed Res Int. 2014;2014:580675. doi: 10.1155/2014/580675.

12. Farinon CB, Pasqualotto GS, Carraro K, Rodrigues-Junior SA. Tooth whitening recovers the color of pre-stained composites. Braz J Oral Sci. 2016;15(2):163-6. doi: 10.20396/bjos.v15i2.8648755.

13. Pecho OE, Martos J, Pinto KVA, Pinto KVA, Baldissera RA. Effect of hydrogen peroxide on color and whiteness of resin-based composites. J Esthet Restor Dent. 2019 Mar;31(2):132-9. doi: 10.1111/jerd.12443.

14. Goldberg M, Grootveld M, Lynch E. Undesirable and adverse effects of tooth-whitening products: a review. Clin Oral Invest. 2010 Feb;14(1):1-10. doi: 10.1007/s00784-009-0302-4.

15. International Standard Organization. ISO 4049:2009-10. Dentistry-Polymer-based restorative materials. 2009

16. Dalla-Vecchia KB, Taborda TD, Stona D, Pressi H, Burnett Júnior LH, Rodrigues-Junior SA. Influence of polishing on surface roughness following toothbrushing wear of composite resins. Gen Dent. 2017 Jan-Feb;65(1):68-74.

17. Santos PA. [Infuence of the light source on color stability of a compoiste resin. Effect of storage medium and storage times] [thesis]. Araraquara: São Paulo State University "Júlio de Mesquita Filho"; 2008. Portuguese.

18. Biazuz J, Zardo P, Rodrigues-Junior SA. Water sorption, solubility and surface roughness of resin surface sealants. Braz J Oral Sci. 2015;14(1):27-30. doi: 10.1590/1677-3225v14n1a06.

19. Pérez MM, Pecho OE, Ghinea R, Pulgar R, Della Bona A. Recent advances in color and whiteness evaluations in dentistry. Cur Dent. 2019;1(1):23-9. doi: 10.2174/2542579X01666180719125137.

20. Pérez MM, Ghinea R, Rivas MJ, Yebra A, Ionescu AM, Paravina RD, et al. Development of a customized whiteness index for dentistry based on CIELAB color space. Dent Mater. 2016 Mar;32(3):461-7. doi: 10.1016/j.dental.2015.12.008

21. Jorge OS, de Arruda CNF, Torrieri RT, Vivanco RG, Pires-de-Souza FCP. Over-the-counter bleaching agentes can help with tooth whitening maintenance. J Esthet Restor Dent. 2020 Jul 6. doi: 10.1111/jerd.12617.

22. Drummond JL. Degradation, fatigue and failure of resin dental composite materials. J Dent Res. 2008 Aug;87(8):710-9. doi: 10.1177/154405910808700802.

23. Oliveira ALBM, Botta AC, Campos JADB, Garcia PPNS. Influence of light curing units and fluoride mouthrinse on morphological surface and color stability of a nanofilled composite resin. Microsc Res Tech. 2014 Nov;77(11):941-6. doi: 10.1002/jemt.22421.

24. Münchow EA, Ferreira ACA, Machado RMM, Ramos TS, Rodrigues-Junior SA, et al. Effect of acidic solutions on the surface degradation of a micro-hybrid composite resin. Braz Dent J. 2014;25(4):321-6. doi: 10.1590/0103-6440201300058.

25. Lago M, Mozzaquatro LR, Rodrigues C, Kaizer MR, Mallmann A, Jacques LB. Influence of bleaching agentes on color and translucency of aged resin composites. J Esthet Restor Dent. 2017 Sep;29(5):368-77. doi: 10.1111/jerd.12261..

26. Rodrigues APM, Klein MC, Dall Agnol MA, Rodrigues-Junior SA. In vitro tooth whitening effectiveness of whitening mouth rinses. Braz J Oral Sci. 2020;19:e206779. doi.org/10.20396/bjos.v19i0.8656779.

27. Müller JA, Rohr N, Fischer J. Evaluation of ISO 4049: water sorption and water solubility of resin cements. Eur J Oral Sci. 2017 Apr;125(2):141-50. doi: 10.1111/eos.12339. 